\title{
Gênero e psicologia na História da Psicologia
}

\section{Gender and psychology on the History of Psychology}

Género y psicología en la Historia de la Psicología

\author{
Anna Christina Porto Maia Passarelli* \\ Faculdade Pitágoras, Betim, Minas Gerais, Brasil

\section{Rodrigo Lopes Miranda**} \\ Universidade de São Paulo - USP, Ribeirão Preto, São Paulo, Brasil
}

Portugal, F. T. \& Jacó-Vilela, A. M. (Org.). Clio-Psyché: Gênero, psicologia, história. Rio de Janeiro: NAU Editora, 2012. 336p.

De acordo com alguns historiadores, a interrogação ao passado pode ser movida por problemas contemporâneos. Tal visão nos induziria, por consequência, a produzir possibilidades interpretativas do fenômeno presente (e.g., Ariès, 1978/2005). Podemos inserir as preocupações da obra "Clio-Psyché: Gênero, psicologia, história", organizada por Francisco Teixeira Portugal e Ana Maria Jacó-Vilela, nesta perspectiva. No livro, notamos dois aspectos que ocorrem paralelamente, embora sejam divergentes: a busca pela superação de diversos tipos de preconceito na sociedade e a contínua ocorrência de episódios de desrespeito aos direitos humanos e de violência de gênero.

As questões de gênero são um tema recorrente em noticiários, especialmente no que se refere aos abusos com o gênero feminino ou com os transgêneros. Citem-se, como ilustração, os resultados de pesquisa desenvolvida pelo Instituto de Pesquisa Econômica Aplicada (Ipea), no qual $26 \%$ dos brasileiros concordavam com afirmações violentas e preconceituosas contra as mulheres. O conceito de gênero, na história da psicologia, é uma temática importante, cujo desenvolvimento tem se fortalecido, desde o final de 1980. Um exemplo disso é o trabalho de Furumoto (1989), que aborda a história das mulheres, na psicologia, como uma forma de fazer uma "nova história" da psicologia. Uma história crítica, que possibilita dar vozes às mulheres que foram sujeitos atuantes na psicologia, no passado. Além disso, na atualidade, obras importantes sobre as 
relações históricas entre as ciências humanas - especialmente a psicologia - e as questões de gênero têm sido publicadas (e.g., Rutherford, Capdevila, Undurti, \& Palmary, 2011). Diante disso, notamos a relevância da obra de Portugal e Jacó-Vilela (2012) nos diálogos historiográficos sobre as relações entre psicologia e gênero. Segundo os organizadores:

Pretendíamos organizar textos que abordassem, de modo variado quanto a seus locais de emergência, seus referenciais teóricos e seus locais de investimento, como gênero, história e psicologia se encontravam para atuar sobre problemas contemporâneos envolvidos com a produção e a manutenção de desigualdades (Portugal \& Jacó-Vilela, 2012, p. 14)

Fazer história a respeito das formas como a ciência psicológica descreve e analisa tais aspectos pode trazer esclarecimentos a respeito de como a comunidade científica e a sociedade se organizam em torno dos conflitos entre o preconceito e a demanda de respeito aos direitos humanos, atualmente. A obra versa sobre este fazer e é fruto das discussões e apresentações que ocorreram no encontro do Clio-Psyché: Programa de estudos e pesquisas em história da psicologia, sediado na Universidade do Estado do Rio de Janeiro (UERJ), em 2010. O encontro se ocupou do tema gênero e propôs articulações entre a psicologia, a história e áreas afins.

O livro é formado por dezesseis capítulos, acrescidos de dois textos iniciais: um Prefácio, de autoria de Marina Massimi e um texto reflexivo inicial, de autoria dos organizadores, que cumpre o papel de introduzir o campo como descrito nos parágrafos acima. Do total de capítulos, sete foram escritos por pesquisadores vinculados a instituições estrangeiras, de diversos países, tais como: Canadá, Espanha, Portugal, Peru e Argentina. A obra possui três partes: a primeira apresenta capítulos que discutem a interferência recíproca entre psicologia e feminismo. Os autores discutem percursos de figuras importantes na história da psicologia e de como seu trabalho foi influenciado e influenciou o feminismo, historicamente. $\mathrm{Na}$ segunda parte, a história é contada através da narrativa de vidas de educadoras, psicólogas e instituições da área. Na terceira parte, os autores discorrem a respeito de fatos, locais e acontecimentos importantes da história da psicologia. O encerramento do livro é feito com um depoimento de Monique Augras, professora de importante participação na concretização da psicologia, no Brasil. O depoimento foi dado no IX Encontro do Programa de estudos e pesquisas em história da psicologia.

O conjunto da obra auxilia na compreensão mais abrangente tanto da história, quanto da aplicação dos conceitos de gênero e de feminismo, na psicologia. Os capítulos abordam questões gerais 
históricas e, gradativamente, tratam de temáticas específicas, tais como histórias de personalidades e instituições e questões filosóficas acerca do tema. Selecionamos dois exemplos que nos auxiliam a compor um dos objetivos do livro organizado por Portugal e JacóVilela: contribuir para a articulação entre os saberes da história da psicologia e áreas afins, além de expandir as discussões relacionadas a estes campos e ao conceito de gênero. Assim, observamos que existem autores de diferentes gêneros e de diferentes localidades procurando entender as relações históricas entre psicologia e gênero.

O primeiro exemplo é o texto "O feminismo precisa da Psicologia? Reconstruindo a história de uma relação", escrito por Alexandra Rutherford, que abre a obra com questionamentos que irão permear o conteúdo dos capítulos seguintes. Com o objetivo de analisar tais questionamentos, a autora inicia apontando o fato de que existem perspectivas que apresentam a psicologia norte-americana com parcas influências de críticas feministas. Dessa forma, haveria um distanciamento entre psicologia e feminismo, nos debates e posicionamentos norte-americanos. Rutherford cita autores do final da década de 1980 e início da década de 1990 que questionam se tal distanciamento seria possível e qual seria, então, a relação entre a psicologia e o feminismo. Em que condições e de que forma essa relação aconteceria? Seria possível que a psicologia abordasse demandas do gênero feminino sem interagir com as teorias feministas? Endereçando respostas a tais perguntas, a autora afirma:

Eu argumento que não se pode entender a evolução do gênero e das relações de gênero, olhando apenas para a história do feminismo, ou só para a história da psicologia. Uma revisão histórica revela os papéis intensamente co-instituintes que feminismo e psicologia têm desempenhado na construção de gênero, e mostra a futilidade conceitual, e prática, das tentativas de desengajá-los dessa dinâmica. (Rutherford, 2012, p. 24)

A partir desta premissa, ela apresenta três exemplos de interação entre feminismo e psicologia nas histórias de Leta Hollingworth, Georgene Seward e Naomi Weisstein.

Leta Hollingworth desempenhou um papel importante na percepção de novas subjetividades de gênero - fruto da insatisfação com a falta de oportunidades para as mulheres, devido às diferenças de gênero e do preconceito. Ela buscou adquirir conhecimento científico a respeito das diferenças de gênero na psicologia, de maneira empírica, durante boa parte de sua vida profissional. Já Georgene Seward teve como contexto a exclusão das mulheres na psicologia do esforço da II Grande Guerra e dificuldades na busca por vagas para ingresso na carreira docente. Ela desenvolveu estudos sobre impactos das 
diferenças biológicas e sociais no trabalho feminino e colocou a II Guerra como fonte de oportunidades de trabalho e reconhecimento. Ambas fizeram parte do movimento constituído pelas primeiras psicólogas feministas empiristas. Elas atuavam convictas de que, se pesquisas científicas fossem feitas cuidadosamente, os resultados iriam desmantelar as suposições enviesadas e não cientificas que formavam a base das crenças mais comuns na época.

A partir de 1968, Naomi Weisstein publicou artigos questionando injustiças cometidas contra as mulheres e a falta de reconhecimento da psicologia como parte do problema. Sugeria que a psicologia não proporcionava conhecimento expressivo da mulher, por desconsiderar muitas vezes o contexto social e não reunir evidências científicas para embasar suas teorias. Na década de 1970, estereótipos de gênero tradicionais eram frequentemente usados como base para categorias diagnósticas, as quais patologizavam mulheres que se encaixavam neles, sendo que, ao mesmo tempo, mulheres que não concordavam com tais estereótipos eram vistas como desviantes e perturbadas.

A partir da trajetória destas três mulheres, Rutherford descreve formas diferentes pelas quais o feminismo e a psicologia interagem, afirmando que investigar historicamente tal relação pode trazer descobertas a respeito das diferenças de gênero que permeiam as relações humanas. Ao final do capítulo, fica a reflexão sobre o constante diálogo realizado entre os dois campos, que inviabiliza uma análise parcial do relacionamento: é preciso olhar tanto para a psicologia, quanto para o feminismo. Segundo Rutherford, não é possível separar o projeto do feminismo, transformar a psicologia, do projeto da psicologia feminista, modificar a sociedade. A psicologia não é independente do contexto social e participa, também, da construção da sociedade.

Nosso segundo exemplo é o capítulo de Alexandre de Carvalho Castro, intitulado "Táticas disciplinares, trajetórias feministas e a emergência do ensino industrial", cujo objetivo é sistematizar aspectos da emergência e constituição da psicologia, no Brasil, a partir de um viés foucaultiano. O trabalho analisa a relevância histórica da relação entre ensino industrial e psicologia. De acordo com Castro (2012): “... a relação da psicologia com o ensino industrial possui relevância histórica que ainda não foi suficientemente investigada" (p.101). Para o autor, essa relação serviria à organização racional do trabalho. Por meio do ensino industrial seria possível avaliar os trabalhadores mais aptos a irem para o mercado de trabalho. O capítulo de Castro dialoga com outros autores da história da psicologia, que indicam esforços feministas na disciplina psicológica, contra barreiras e pressupostos machistas que podem ser encontrados desde o início de sua constituição (e.g., Pickren \& Rutherford, 2010). Castro acrescenta a essa história barreiras machistas sustentadas por empecilhos sociais e políticos, 
influenciando a consolidação da mulher no mercado de trabalho, ainda na década de 1930 .

Castro utiliza o caso da Escola Normal de Artes e Ofícios Wenceslau Brás, instalada no Rio de Janeiro, em 1918, cuja proposta inicial se preocupava em ensinar uma profissão aos pobres do sexo masculino. Inicialmente, a Escola Wenceslau Brás não receberia alunas. Porém, há registros de que alunas passaram pela instituição, fato que levanta uma problemática em relação ao ensino feminino: as mulheres eram, então, preparadas para o trabalho industrial ou para trabalhos manuais? Esse debate está ancorado no governo de Getúlio Vargas, no qual o interesse da Escola se voltou para levar para a indústria os alunos mais bem indicados. Segundo Castro (2012):

a interpretação se a Escola Wenceslau Brás aceitava discentes do sexo feminino, depende de entender o objetivo da Escola Wenceslau Brás, a natureza do ensino industrial e dos fatores que levaram à emergência da escola (p. 111).

Os documentos utilizados pelo autor foram textuais, referentes ao período de 1921 a 1937, além de três entrevistas com ex-alunas da Escola. A análise dessas fontes indica que o espaço para as mulheres, na Escola, era restrito. Elas não eram aceitas desde o início do funcionamento da instituição. Apesar disso, com o decorrer de uma série de questões políticas, administrativas e institucionais, observase o número de discentes do sexo feminino predominando sobre os do sexo masculino.

Castro contextualiza a constituição e emergência da Escola, buscando descrever em que condições é possível uma escola, que se propõe receber discentes do sexo feminino que se formariam professoras do ensino industrial, acabar, por uma série de circunstâncias, recebendo tais discentes para cursos de trabalhos manuais e economia doméstica. Essa situação, somada ao fato de que o número de alunas superou o número de alunos na Escola, impôs a adoção de algumas práticas disciplinares. O material pesquisado aponta micropenalidades para controle de atrasos, ausências e desatenção. Também foi identificada a interdição do contato entre alunas e alunos. Na análise do Livro de Registros da Escola, foram encontrados, em sua maioria, relatos de punições. O autor finaliza, concluindo que o ensino feminino surgiu na Escola Wenceslau Brás por um arranjo específico de condições e processos administrativos, políticos e educacionais, de forma nenhuma ocorrido repentinamente e/ou desprendido de circunstâncias político-sociais.

A leitura do livro de Portugal e Jacó-Vilela possibilita a compreensão do crescimento histórico do feminismo e do conhecimento a respeito das diferenças de gênero dentro da disciplina psicológica. Ele se apresenta como um "trabalho em progresso" das diferentes autoras e 
autores que o organizaram e que nele contribuíram permitindo incluir informações, pessoas, instituições, etc. que, porventura, ainda não haviam sido pesquisadas. Na obra, notamos capítulos cujo conteúdo descreve a luta feminista e seus avanços, tanto dentro, como fora, da psicologia. Há, também, capítulos que discutem de maneira mais prática o modo como o aumento da participação feminina na sociedade afetou campos como a educação, a política e a saúde. Esse conjunto vai ao encontro daquilo que as pessoas, que se debruçam sobre as questões de gênero, têm consistentemente argumentado: a experiência feminina de desigualdade de gênero deve ser levada em consideração para entender suas vidas (e.g., assédio e discriminação sexual, pobreza, racismo e estresse). O livro favorece a compreensão da história da psicologia e de como essa área se vincula, de forma singular, aos diferentes gêneros humanos. Ele contribui para a leitura de questões importantes na contemporaneidade, a partir do conhecimento do passado. Auxilia, por fim, a observar que o presente e o passado, embora particulares de cada localidade, podem dialogar.

\section{Referências}

Ariès, P. (2005). A História das Mentalidades. Em J. Le Goff (Org.). A História Nova, 5a ed. (pp. 205-236). São Paulo: Martins Fontes. Original publicado em 1978.

Castro, A. C. (2012). Táticas Disciplinares, Trajetórias Femininas e a Emergência do Ensino Industrial. Em F. T. Portugal \& A. M. Jacó-Vilela (Orgs.). Clio-Psyché: Gênero, psicologia, história (pp. 101-115). Rio de Janeiro: NAU Editora.

Furumoto, L. (1989). The New History of Psychology. Em I. Cohen (Org.). The G. Stanley Hall Lecture Series, vol. 9 (pp. 9-34). Washington, D.C.: American Psychological Association.

Pickren, W. \& Rutherford, A. (2010). A History of Modern Psychology in Context. Hoboken: John Wiley \& Sons, Inc.

Portugal, F. T. \& Jacó-Vilela, A. M. (2012) (Orgs.). Clio-Psyché: Gênero, psicologia, história. Rio de Janeiro: NAU Editora.

Rutherford, A. (2012). O Feminismo precisa da Psicologia? Reconstruindo a história de uma relação. Em F. T. Portugal \& A. M. Jacó-Vilela (Orgs.). Clio-Psyché: Gênero, psicologia, história (pp. 23-41). Rio de Janeiro: NAU Editora.

Rutherford, A., Capdevila, R, Undurti, V. \& Palmary, I. (2011) (Orgs.) Handbook of International Feminisms: Perspectives on psychology, women, culture and rights. Springer: Nova Iorque.

Endereço para correspondência

Anna Christina Porto Maia Passarelli

Faculdade Pitágoras 
Av. J uscelino Kubitschek, 229, CEP 32600-225, Betim - MG, Brasil

Endereço eletrônico: anna.passarelli@gmail.com

Rodrigo Lopes Miranda

Av. Bandeirantes, 3900, CEP 14040-901, Ribeirão Preto - SP, Brasil

Endereço eletrônico: dingoh@gmail.com

Recebido em: 19/07/2014

Aprovado em: 25/07/2014

\section{Notas}

* Mestre em Psicologia pelo Programa de Pós-Graduação em Psicologia da Universidade Federal de Minas Gerais (UFMG). Professora da Faculdade Pitágoras.

** Pós-doutorando no Departamento de Psicologia da Faculdade de Filosofia, Ciências e Letras da Universidade de São Paulo, Campus Ribeirão Preto (USP-RP). Bolsista de FAPESP (No. 2013/22946-3). Mestre e Doutor em Educação pelo Programa de Pós-Graduação em Educação da Faculdade de Educação da Universidade Federal de Minas Gerais (UFMG). 